\title{
Aplikasi Metode Geolistrik untuk Pendugaan Air Bawah Tanah Desa Karanganyar Kecamatan Bantaran Kabupaten Probolinggo Jawa Timur
}

\author{
Fajar Rakhmanto ${ }^{1}$, Arif Yudo Pradana ${ }^{2}$, Nicho Andreas Fernando ${ }^{3}$ \\ ${ }^{1}$ Institut Teknologi Nasional Malang \\ ${ }^{2}$ Geografi, Fakultas Ilmu Sosial, Universitas Negeri Malang \\ ${ }^{3}$ PT Geomedia Sinergi \\ E-mail : fajarr.geosains@gmail.com
}

\begin{abstract}
ABSTRAK
Desa Karanganyar, Kecamatan Bantaran, Kabupaten Probolinggo merupakan salah satu daerah kekeringan. Daerah ini tersusun oleh lapisan produk Gunungapi Tengger yang terdiri dari tuff, breksi gunungapi, lava, dan lahar. Kondisi tersebut memungkinkan daerah tersebut mengalami krisis akan air tanah karena lapisan produk gunungapi memiliki karakteristik impermiabel atau kedap air. Untuk itu diperlukan penelusuran mengenai informasi dasar tentang letak keberadaan air tanah dengan cara survey geofisika menggunakan metode geolistrik resistivitas. Penelitian ini bertujuan untuk mengkaji potensi keberadaan air tanah di lokasi penelitian dan mengetahui kondisi litologi bawah permukaan dengan metode geolistrik tahanan jenis menggunakan konfigurasi Wenner dan Schlumberger. Berdasarkan hasil penelitian diketahui litologi penyusun di daerah pengukuran berupa batuan vulkanik (lempung tuffan, tuff, lahar tuffan, breksi, dan lava). Batuan yang berpotensi mengandung akuifer yaitu batuan lahar tuffan. Batuan lahar tuffan tersebar di ketiga titik pengukuran sehingga ketiga titik tersebut memiliki potensi akuifer. Pada titik KRA-1 akuifer yang dapat dijumpai diduga terdapat pada kedalaman 37,1 - 102,3 meter dengan nilai resistivitas 60,3 - 171,5 ohm meter, titik KRA-2 pada kedalaman 92,8 - 143,9 meter dengan nilai resistivitas 50,2 - 62,9 ohm meter, dan titik KRA-3 pada kedalaman 63,4 - 133,15 meter dengan nilai resistivitas $62,6-119,5 \mathrm{ohm}$ meter.
\end{abstract}

Kata Kunci: karanganyar; bantaran; probolinggo; geolistrik; akuifer

\begin{abstract}
Karanganyar Village, Bantaran District, Probolinggo Regency is one of the drought areas. This area is composed of layers of Tengger Volcano products consisting of tuff, volcanic breccias, lava, and lava. These conditions allow the area to experience a crisis of groundwater because the volcanic product layer has impermiable or waterproof characteristics. For this reason it is necessary to search for basic information about the location of the presence of groundwater by geophysical survey using the resistivity geoelectric method. This study aims to examine the potential presence of groundwater in the study site and determine the conditions of subsurface lithology with the geoelectric resistivity method using the Wenner and Schlumberger configurations. Based on the research results, it is known that the lithology of the constituents in the measurement area is volcanic rock (tuffan clay, tuff, lava tuffan, breccia, and lava). Rocks that have the potential to contain aquifers are tuffan lava rocks. Tuffan lava rocks are scattered in all three measurement points so that all three points have an aquifer potential. At the point of KRA-1 aquifer that can be found is suspected to be at a depth of 37.1 - 102.3 meters with a resistivity value
\end{abstract}

Cara Mengutip : Rakhmato, F., Pradana A. Y., Fernando, N. A. (2019). Aplikasi Metode Geolistrik untuk Pendugaan Air Bawah Tanah Desa Karanganyar Kecamatan Bantaran Kabupaten Probolinggo Jawa Timur. JAST : Jurnal Aplikasi Sains dan Teknologi, 3 (2),146-152. doi:http://dx.doi.org/10.33366/jast.v3i2.1571 
of 60.3 - 171.5 ohm meters, a KRA-2 point at a depth of 92.8 - 143.9 meters with a value of resistivity $50.2-62.9 \mathrm{ohm}$ meters, and KRA-3 points at depths of $63.4-133.15$ meters with resistivity values of $62.6-119.5 \mathrm{ohm}$ meter.

Keywords : karanganyar; bantaran; probolinggo; geoelectric; aquifer

\section{PENDAHULUAN}

Salah satu wilayah di Indonesia yang tergolong memiliki cenderungan sulit akan kebutuhan air tanah adalah Desa Karanganyar, Kecamatan Bantaran, Kabupaten Probolinggo yang menjadi fokus penelitian kali ini. Desa ini terletak di lereng timur dari Gunung Bromo. Secara umum kondisi topografi daerah ini berupa dataran hingga perbukitan bergelombang. Jika dilihat berdasarkan peta geologi lembar Probolinggo, diketahui daerah ini tersusun oleh tanah jenis Qvt yang berasal dari batuan gunungapi Tengger yang terdiri dari Tuf, breksi gunungapi, lava, dan lahar [1]. Dengan melihat kondisi tersebut, maka tidak mengherankan jika daerah tersebut cenderung mengalami krisis akan airtanah. Sehingga masyarakat kesulitan untuk mendapatkan suplai air bersih untuk memenuhi kebutuhan hidup sehariharinya. Kondisi yang lebih parah akan terjadi apabila telah tiba musim kemarau, karena pada saat itu air bersih akan sangat langka untuk diperoleh. Seperti yang diketahui, daerah yang lapisan penyusunnya berupa produk gunungapi cenderung memiliki karakteristik permeable atau kedap air. Dengan karakteristik tersebut akan sulit ditemukan air tanah bebas yang bisa ditemukan dengan cara mengali sumur biasa. Untuk menemukan lapisan akuifer, perlu ditempuh dengan cara pengeboran. Pembuatan sumur bor merupakan salah satu cara agar harapan masyarakat untuk memenuhi kebutuhan air bersih di Desa Karanganyar dapat terpenuhi. Untuk itu diperlukan penelusuran mengenai informasi dasar tentang letak keberadaan airtanah. Informasi tersebut memberikan penjelasan tentang ketebalan lapisan akuifer, letak, dan lapisan batuan yang mengandung airtanah di dalamnya. Untuk memperoleh informasi tersebut dilakukan dengan cara melakukan survey geologi bawah permukaan dengan cara melakukan survey pemetaan geofisika menggunakan alat geolistrik. Pengukuran geolistrik dimaksudkan untuk mendeteksi adanya lapisan akuifer airtanah di daerah penelitian dengan cara mengetahui penyebaran, jenis litologi, kedalaman dan ketebalan lapisan batuan pembawa airtanah, baik secara horizontal maupun vertikal.

\section{METODE KEGIATAN}

Metode geolistrik resistivitas merupakan suatu cabang metode permukaan yang digunakan dalam eksplorasi dangkal. Geolistrik resistivitas digunakan untuk menentukan kedalaman batuan dasar, pencarian reservoir air, dan digunakan dalam eksplorasi geothermal. Metode geolistrik juga efektif dalam eksplorasi mineral logam yang memiliki nilai kontras resistivitas yang besar dengan batuan sekitar. Prinsip pengukuran metode geolistrik adalah dengan mengukur sifat kelistrikan batuan [1] 
Arus listrik searah ataupun bolak-balik berfrekuensi rendah dialirkan ke dalam bumi melalui kontak dua elektroda arus (C1C2), kemudian diukur besarnya potensial melalui dua elektroda potensial (P1P2). Dengan mengetahui besar arus dan potensial, maka dapat diketahui besar tahanan jenis dari media (batuan) yang dilaluinya [2]. Metodologi yang dipakai pada penelitian kali ini yaitu pengambilan data secara langsung di lapangan (primer) dengan cara melakukan pengukuran geolistrik di lapangan untuk mendapatkan data arus dan beda potensial yang nantinya digunakan untuk menentukan tingkat resistivitasnya. Penelitian ini dilaksanakan pada tanggal 19-20 Agustus 2019. Lokasi penelitian berada di Desa Karanganyar, Kecamatan Bantaran, Kabupaten Probolinggo. Koordinat lokasi pengukuran terdiri dari 2 lokasi dengan masing-masing terdiri dari 3 titik pengukuran pada tabel 1 .

Tabel 1. Koordinat pengukuran geolistrik

\begin{tabular}{|c|c|c|c|}
\hline \multicolumn{4}{|c|}{ Pokmas Pucuk Bersemi (Kode A) } \\
\hline No & Titik & Koordinat & Elerasi (m) \\
\hline 1 & KRA-I & $7^{05} 52273^{\prime \prime S} 113^{\circ} 1040.9^{\prime \prime} \mathrm{E}$ & $88 \mathrm{~m}$ \\
\hline 2 & KRA-2 & 705219.4'S $113^{\circ} 1023.11^{\prime \prime E}$ & $95 \mathrm{~m}$ \\
\hline 3 & KRA-3 & $7^{\circ} 52^{\circ} 42.9^{\circ} \mathrm{S} 113^{\circ} 10^{\prime} 13.5^{\circ} \mathrm{E}$ & $110 \mathrm{~m}$ \\
\hline
\end{tabular}

Akuisisi data pada penelitian ini yaitu menggunakan metode sounding dengan konfigurasi wenner dan schlumberger. Pengukuran dengan konfigurasi Wenner dilakukan di titik KRA-1, sedangkan pengukuran dengan konfigurasi Schlumberger dilakukan di titik KRA-2 dan KRA-3. Setelah melakukan proses akuisisi data dilapangan diperoleh nilai tegangan (V), kuat arus (I), koordinat titik datum, jarak elektroda (a), resistansi (R), kedalaman antar lapisan (n1 sampai nn). Kemudian, dicari besar faktor geometri (k) untuk masing-masing lintasan. Setelah diperoleh nilai k, kemudian mencari nilai resistivitas $(\rho)$. Data hasil pengukuran diolah untuk mengolah data awal berupa nilai kuat arus (I), beda potensial $(\Delta \mathrm{V})$, dan nilai spasi dari konfigurasi Schlumberger, a untuk jarak elektroda potensial dan $b$ untuk jarak elektroda arus, dan besar faktor geometri (K). Dengan memasukkan variabel tersebut akan didapatkan besar resistivitas semu ( $\rho$ a). Berdasarkan resistivitas yang diperoleh tersebut, maka dapat diketahui tingkat ketebalan, variasi litologinya, dan tingkat kedalaman lapisan beserta penyebarannya, termasuk ada atau tidaknya lapisan yang mengandung air tanah di dalamnya.

Adapun lokasi tersebut dapat dilihat pada Gambar 1.

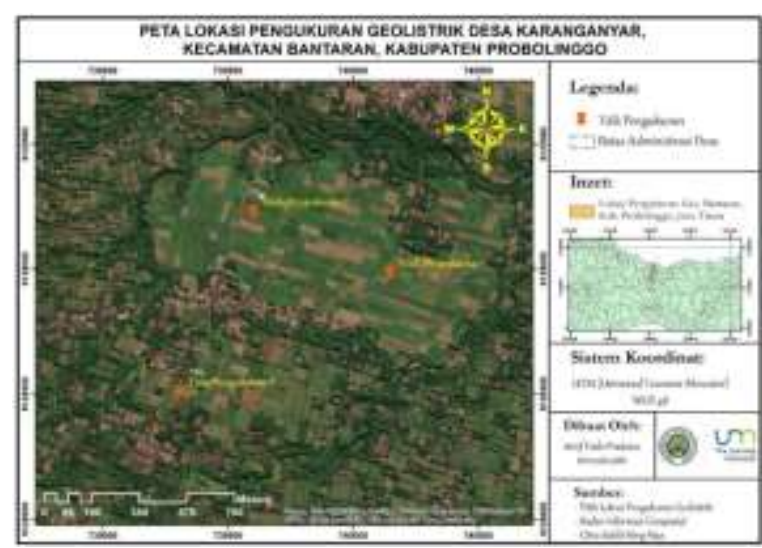

Gambar 1. Peta lokasi penelitian

\section{KARYA UTAMA}

Hasil dari pengukuran geolistrik dapat dilihat pada Gambar berikut :

$\underline{\text { KRA-1 }}$ 

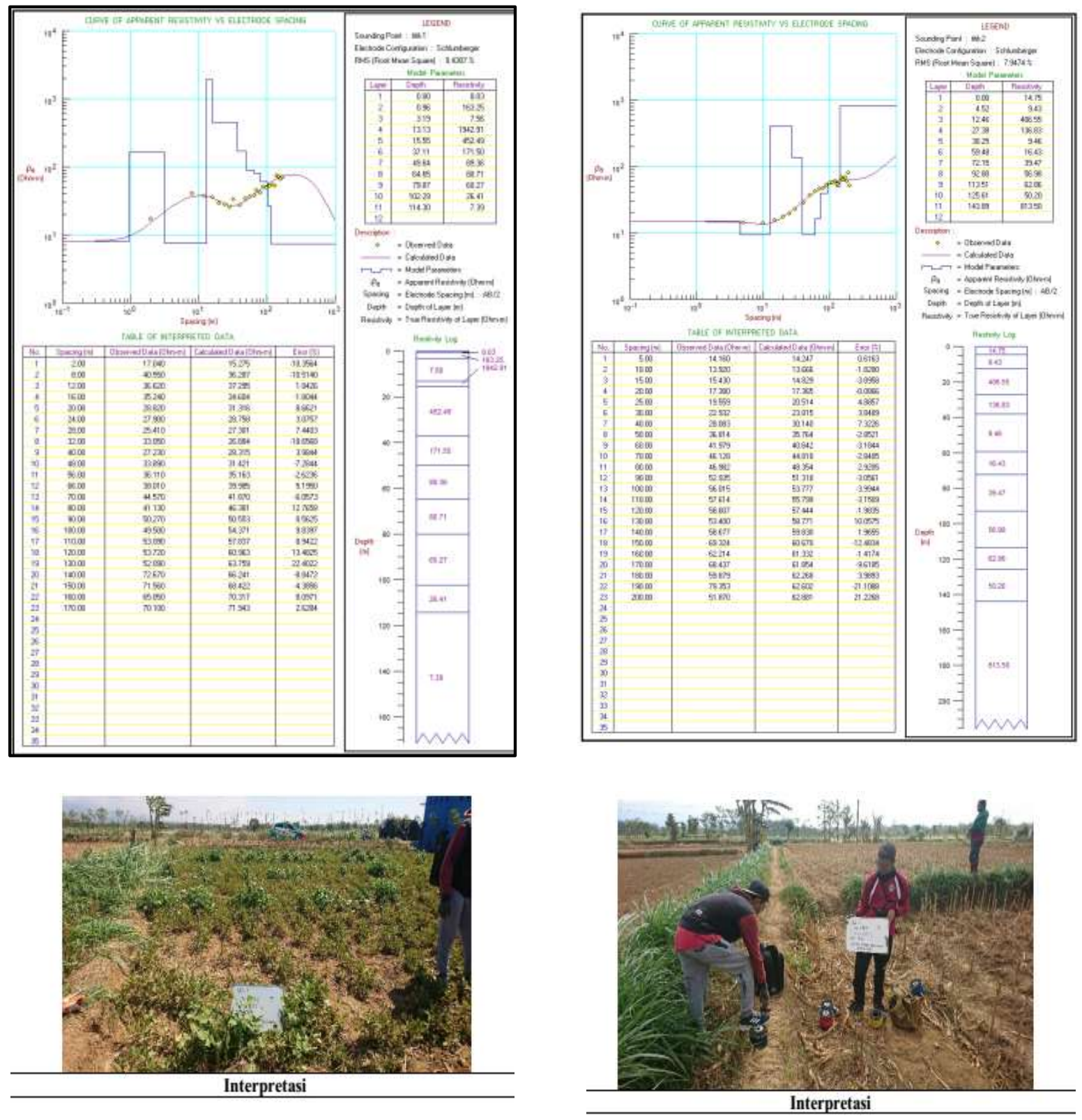

\begin{tabular}{|c|c|c|c|c|}
\hline \multicolumn{2}{|c|}{ Kedalaman (m) } & Ketebalan & Rho $(\boldsymbol{\rho}) \mathbf{\Omega m}$ & Keterangan \\
\hline 0 & 1 & 1 & 8 & Lempung Tuffan \\
\hline 1 & 3.2 & 2.2 & 163.3 & Lahar Tuffan \\
\hline 3.2 & 13.1 & 9.9 & 7.6 & Lempung Tuffan \\
\hline 13.1 & 15.6 & 2,5 & 1942.9 & Lava \\
\hline 15.6 & 37.1 & 21.5 & 452.5 & Breksi \\
\hline 37.1 & 49.6 & 12.5 & 171.5 & Lahar Tuffan \\
\hline 49.6 & 64.7 & 15.1 & 89.4 & Lahar Tuffan \\
\hline 64.7 & 79.9 & 15.2 & 80.7 & Lahar Tuffan \\
\hline 79.9 & 102.3 & 22.4 & 60.3 & Lahar Tuffan \\
\hline 102.3 & 114.3 & 12 & 26.4 & Tuff \\
\hline 114.3 & 135 & 20.7 & 7.4 & Lempung Tuffan \\
\hline
\end{tabular}

Gambar 1. Lokasi dan Hasil interpretasi titik geolistrik KRA-1

\begin{tabular}{|c|c|c|c|c|}
\hline \multicolumn{2}{|c|}{ Kedalaman (m) } & Ketebalan & Rho $(\boldsymbol{\rho}) \mathbf{\Omega} \mathbf{m}$ & Keterangan \\
\hline 0 & 4.5 & 4.5 & 14.8 & Lempung tuffan \\
\hline 4.5 & 12.5 & 8 & 9.43 & Lempung tuffan \\
\hline 12.5 & 27.4 & 14.9 & 406.6 & Breksi \\
\hline 27.4 & 38.3 & 10.9 & 136.8 & Lahar Tuffan \\
\hline 38.3 & 59.5 & 21.2 & 9.5 & Lempung Tuffan \\
\hline 59.5 & 72.2 & 12.7 & 16.4 & Lempung Tuffan \\
\hline 72.2 & 92.8 & 20.6 & 39.5 & Tuff \\
\hline 92.8 & 113.5 & 20.7 & 57 & Lahar Tuffan \\
\hline 113.5 & 125.6 & 12.1 & 62.9 & Lahar Tuffan \\
\hline 125.6 & 143.9 & 18.3 & 50.2 & Lahar Tuffan \\
\hline 143.9 & 155 & 11.1 & 813.5 & Breksi \\
\hline
\end{tabular}

Gambar 2. Lokasi dan Hasil interpretasi titik geolistrik KRA-2 

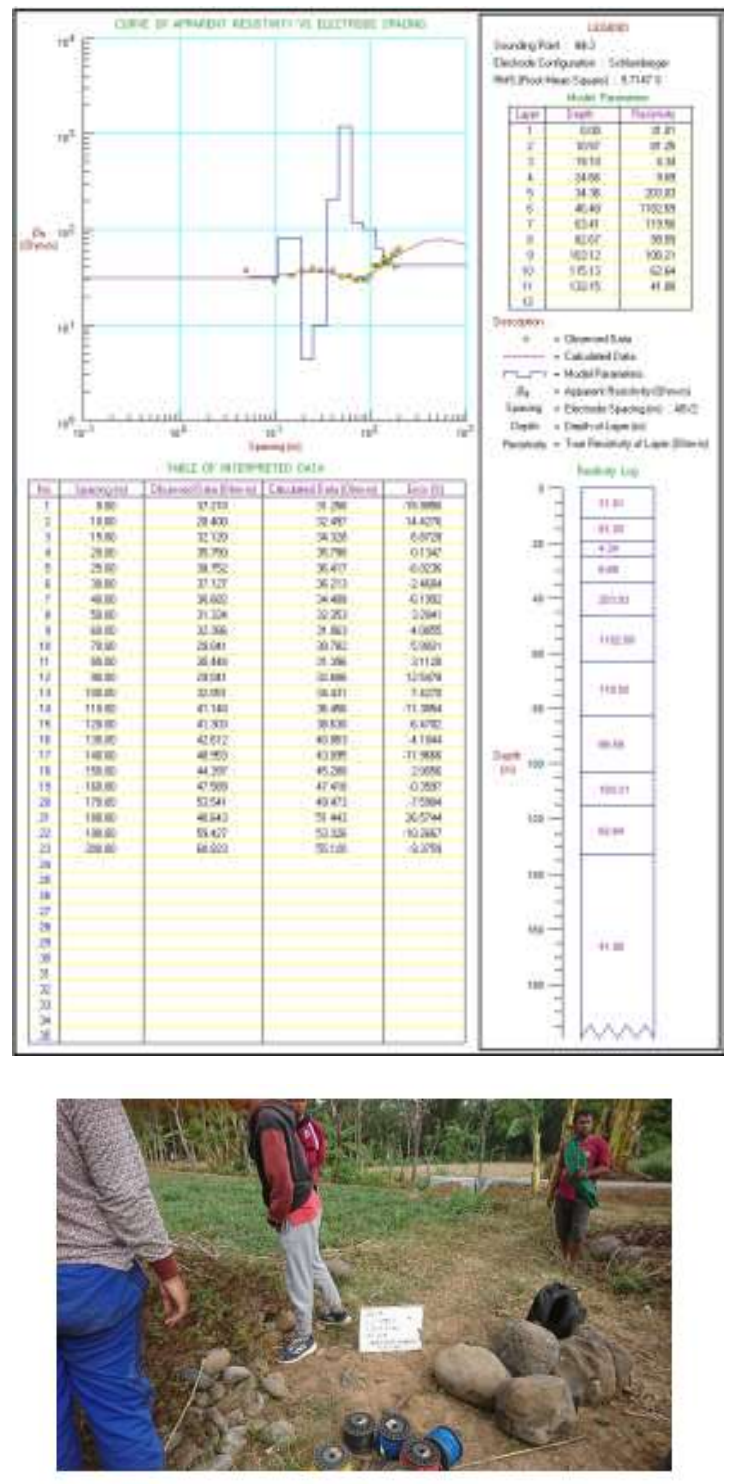

\begin{tabular}{|c|c|c|c|c|}
\hline \multicolumn{5}{|c|}{ Interpretasi } \\
\hline \multicolumn{2}{|c|}{ Kedalaman (m) } & Ketebalan & Rho $(\rho) \Omega m$ & Keterangan \\
\hline 0 & 10.6 & 10.6 & 31 & Tuff \\
\hline 10.6 & 19.1 & 8.5 & 81.3 & Lahar Tuffan \\
\hline 19.1 & 24.7 & 5.6 & 4.3 & Lempung Tuffan \\
\hline 24.7 & 34.4 & 9.7 & 9.7 & Lempung Tuffan \\
\hline 34.4 & 46.4 & 12 & 203 & Breksi \\
\hline 46.4 & 63.4 & 17 & 1182.7 & Lava \\
\hline 63.4 & 82.7 & 19.3 & 1195 & Lahar Tuffan \\
\hline 82.7 & 103.1 & 20.4 & 99.6 & Lahar Tuffan \\
\hline 103.1 & 115.1 & 12 & 100.2 & Lahar Tuffan \\
\hline 115.1 & 133.15 & 18.1 & 62.6 & Lahar Tuffan \\
\hline 133.15 & 145 & 11.85 & 41.9 & Tuff \\
\hline
\end{tabular}

Gambar 3. Lokasi dan Hasil interpretasi titik geolistrik KRA-3

Berdasarkan hasil pengolahan data, secara vertikal diketahui terdapat lapisan yang berbeda berdasarkan pada harga tahanan jenisnya. Setiap lapisan dapat diketahui jenis litologi, ketebalan, dan kedalamannya. Akan tetapi bukan berarti setiap harga tahanan jenis mewakili satu jenis litologi. Hal ini disebabkan harga tahanan jenis dari litologi merupakan harga kisaran. Selain mendasarkan pada harga resistivitasnya, untuk menduga jenis litologi juga didukung oleh data singkapan permukaan.

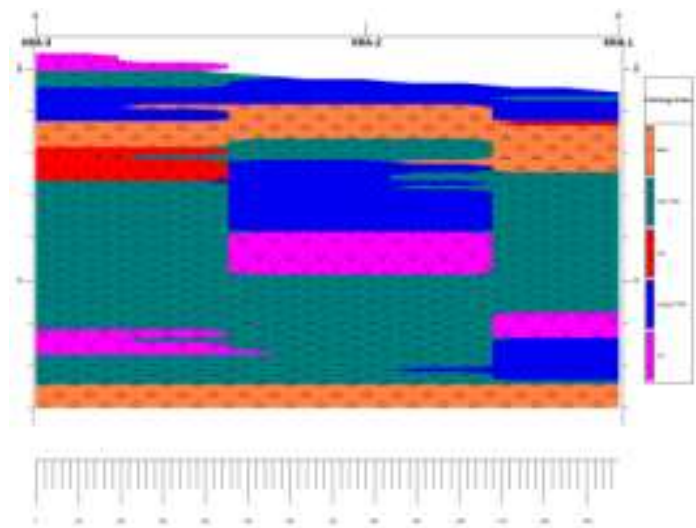

Gambar 4. Pemodelan Sebaran Litologi KRA1, KRA-2, dan KRA-3

Hasil pengukuran geolistrik seperti yang ditunjukkan oleh gambar. menunjukkan harga tahanan jenis daerah penelitian memang cukup terlihat kontras antara litologi breksi/lava dan lahar tuffan yang dimungkinkan sebagai akuifer. Harga tahanan jenis dengan rentangan 50$200 \mathrm{ohm}$ meter mengindikasikan lapisan akuifer (batupasir). Sedangkan harga tahanan jenis tinggi dengan rentangan resistivity antara 200-1000 ohm meter mengindikasikan litologi yang impermeable (breksi atau batuan beku). Berdasarkan harga tahanan jenisnya, ketiga lokasi pengukuran mengindikasikan adanya lapisan akuifer.

\section{ULASAN KARYA}

Titik KRA-1 terletak pada posisi $7^{\circ} 52 ' 27.3^{\prime \prime S} 113^{\circ} 10^{\prime} 40.9^{\prime \prime E ~ d e n g a n ~ e l e v a s i ~}$ 88 mdpl. Interpretasi dari data hasil 
penelitian di titik KRA-1 adalah jumlah lapisan bawah permukaan bumi sebanyak 11 lapisan dengan pembacaan kedalaman mencapai $135 \mathrm{~m}$ dan nilai erorr sebesar 9,4\%. Susunan batuan pada titik KRA-1 terdiri dari Lempung Tuffan, Lahar Tuffan, Lava, Breksi, dan Tuff. Pada titik sounding 1, lapisan batuan daerah ini didomniasi oleh batuan lahar tuffan. Lapisan batuan lahar tuffan terletak di lapisan 2, dan lapisan 6 hingga 9. Pada titik ini diperkirakan batuan lahar tuffan merupakan batuan pembawa sifat air tanah. Pendugaan batuan lahar tuffan sebagai batuan penyimpan air didasarkan pada ciri khusus yaitu memiliki nilai resistivitas 60 hingga 170 ohm meter, dimana nilai resistivitas tersebut masuk pada klasifikasi batuan lahar tuffan dengan rentangan nilai $50-200$ ohm meter. Adapun kedalaman akuifer pada titik KRA-1 diperkirakan pada nilai resistivitas 60,3 hingga $171,5 \mathrm{Ohm}$ meter sebagai batas akuifer, kedalaman akuifer berada di kedalaman 37,1- 102,3 meter.

Titik KRA-1 terletak pada posisi 752'19.4"S 113¹0'23.1"E dengan elevasi 95 mdpl. Interpretasi dari data hasil penelitian di titik KRA-2 adalah jumlah lapisan bawah permukaan bumi sebanyak 11 lapisan dengan pembacaan kedalaman mencapai $155 \mathrm{~m}$ dan nilai erorr sebesar $7,9 \%$. Susunan batuan pada titik KRA-2 terdiri dari lempung tuffan, breksi, lahar tuffan. Dan tuff Pada titik sounding 2, lapisan batuan daerah ini didomniasi oleh batuan lahar tuffan. Lapisan batuan lahar tuffan terletak di lapisan 4, dan lapisan 8 hingga 10. Pada titik ini diperkirakan batuan lahar tuffan merupakan batuan pembawa sifat air tanah. Pendugaan batuan lahar tuffan sebagai batuan penyimpan air didasarkan pada ciri khusus yaitu memiliki nilai resistivitas 50,2 hingga 62,9 ohm meter, dimana nilai resistivitas tersebut masuk pada klasifikasi batuan lahar tuffan dengan rentangan nilai 50 - 200 ohm meter. Adapun kedalaman akuifer pada titik KRA-2 diperkirakan pada nilai resistivitas 50 hingga $62 \mathrm{Ohm}$ meter sebagai batas akuifer kedalaman akuifer berada pada kedalaman 92,8 hingga 143,9 meter.

Titik KRA-3 terletak pada posisi $7^{\circ} 52^{\prime} 42.9^{\prime \prime S} 113^{\circ} 10^{\prime} 13.5^{\prime \prime E}$ dengan elevasi 110 mdpl. Interpretasi dari data hasil penelitian di titik KRA-3 adalah jumlah lapisan bawah permukaan bumi sebanyak 11 lapisan dengan pembacaan kedalaman mencapai $145 \mathrm{~m}$ dan nilai erorr sebesar 9,7\%. Susunan batuan pada titik KRA-2 terdiri dari Tuff, Lahar Tuffan, Lempung Tuffan, Breksi, dan Lava. Pada titik sounding 3, lapisan batuan daerah ini didomniasi oleh batuan lahar tuffan. Lapisan batuan lahar tuffan terletak di lapisan 2, dan lapisan 7 hingga 10. Pada titik ini diperkirakan batuan lahar tuffan merupakan batuan pembawa sifat air tanah. Pendugaan batuan lahar tuffan sebagai batuan penyimpan air didasarkan pada ciri khusus yaitu memiliki nilai resistivitas 62,6 hingga $119,5 \mathrm{ohm}$ meter, dimana nilai resistivitas tersebut masuk pada klasifikasi batuan lahar tuffan dengan rentangan nilai $50-200$ ohm meter. Adapun kedalaman akuifer pada titik KRA-3 diperkirakan pada nilai resistivitas 62,6 hingga 119,5 Ohm meter sebagai batas akuifer kedalaman akuifer berada pada kedalaman 63,4 hingga 133,15 meter. 


\section{DAMPAK DAN MANFAAT KEGIATAN}

Berdasarkan hasil interpolasi lapisan penyusun di setiap titik pengukuran dapat diketahui lapisan penyusun daerah penelitian berupa lempung tuffan, tuff, lahar tuffan, breksi, dan lava. Dari gambar di atas dapat dilihat secara 2 dimensi bahwa hasil pemodelan dari masingmasing titik pengukuran KRA-1, KRA-2, dan KRA-3 menunjukkan adanya hubungan lapisan akuifer yang hampir merata. Perlapisan batuan di daerah penelitian didominasi oleh lapisan Lahar Tuffan. Lahar Tuffan merupakan lapisan batuan yang banyak mengandung air dan dapat menyerap dan melewati air (akuifer). Sehingga ketiga titik pengukuran di atas diduga memiliki potensi akuifer di bawah permukaannya, walaupun dengan kedalaman yang berbeda.

\section{KESIMPULAN}

Berdasarkan hasil penelitian yang telah dilakukan, maka dapat disimpulkan bahwa litologi penyusun di daerah pengukuran berdasarkan peta geologi berupa batuan vulkanik (lempung tuffan, tuff, lahar tuffan, breksi, dan lava). Diantara kelima batuan tersebut yang memiliki potensi sebagai batuan penyimpan air adalah batuan lahar tuffan dengan rentangan nilai resistivitas antara $50-200$ ohm meter. Ketiga titik pengukuran masing-masing terindikasi memiliki potensi akuifer dalam.Pada titik KRA-1 akuifer yang dapat dijumpai diduga terdapat pada kedalaman 37,1102,3 meter dengan nilai resistivitas 60,3 - 171,5 ohm meter, titik KRA-2 pada kedalaman 92,8 - 143,9 meter dengan nilai resistivitas $50,2-62,9$ ohm meter, dan titik KRA-3 pada kedalaman 63,4 133,15 meter dengan nilai resistivitas 62,6-119,5 ohm meter. Diketahui akuifer yang paling tebal terletak pada titik KRA3, diikuti oleh titik KRA-1 dan KRA-2

\section{PENGHARGAAN}

Ucapan terima kasih kepada Bapak Solihin selaku konsultan penyandang dana dan perangkat Desa Karanganyar yang telah membantu pelaksanaan di lapangan. Tim Geolistrik dari Geosains Malang yang telah membantu dalam akusisi data.

\section{DAFTAR PUSTAKA}

[1] Suharsono dan T. Suwarti. 1992. Peta Geologi Lembar Probolinggo, Jawa. Pusat Penelitian dan Pengembangan Geologi. Bandung

[2] Dobrin, M.B. dan Savit, C.H., 1988. Introduction to Geophysics Prospecting Fourth Edition, New York.

[3] Winarti. 2013. Metode Geolistrik Untuk Mendeteksi Akuifer Airtanah Di Daerah Sulit Air (Studi Kasus Di Kecataman Takeran, Poncol Dan Parang, Kabupaten Magetan). Journal Angkasa : Jurnal Ilmiah Bidang Teknologi, Vol.5 Nomer 1. STTA. 